\title{
Kemampuan Membaca Cepat Berdasarkan Jenis Kelamin Siswa Kelas VIII SMP Negeri 03 Lebong Tahun Ajaran 2020/2021
}

\author{
Fera Delva \\ (corresponding author) \\ SMP Negeri 03 Lebong \\ Email: feradelva32@gmail.com \\ Dian Eka Chandra Wardhana \\ Program Studi Magister Pendidikan Bahasa Indonesia, Universitas Bengkulu \\ Email: dec.wardhana@unib.ac.id \\ Rokhmat Basuki \\ Program Studi Magister Pendidikan Bahasa Indonesia, Universitas Bengkulu \\ Email: rokhmat.bas@gmail.com
}

\begin{abstract}
APA Citation: Delva, F., Wardhana, D.E.C., \& Basuki, R. (2021). Kemampuan Membaca Cepat Berdasarkan Jenis Kelamin Siswa Kelas VIII SMP Negeri 03 Lebong Tahun Pelajaran 2020/2021. Silampari Bisa: Jurnal Penelitian Pendidikan Bahasa Indonesia, Daerah, dan Asing, 4(1), 143-158. https://doi.org/10.31540/silamparibisa.v4i1.1281
\end{abstract}

\begin{abstract}
Abstrak
Kemampuan membaca cepat merupakan kesanggupan siswa dalam membaca dengan cepat serta dengan pemahaman yang tepat. Semakin baik kemampuan membaca cepat siswa maka akan semakin baik pemahaman terhadap isi bacaan. Akan tetapi, belum diketahuinya apakah ada perbedaan kemampuan membaca cepat antara siswa laki-laki dengan perempuan terhadap teks yang dibacanya. Untuk itu, tujuan penelitian ini adalah untuk mendeskripsikan tingkat kemampuan membaca cepat berdasarkan jenis kelamin siswa kelas VIII SMP Negeri 03 Lebong Tahun Ajaran 2020/2021. Metode penelitian ini menggunakan metode deskriptif kuantitatif. Populasi berjumlah 24 siswa dan sampel adalah seluruh anggota populasi yaitu berjumlah 24 siswa yang terdiri 12 siswa laki-laki dan 12 siswa perempuan. Teknik pengumpulan data menggunakan teknis tes berbentuk tes pilihan ganda. Teknik analisis data dengan cara menghitung pemahaman siswa dan dipersentasekan, menghitung kecepatan efektif membaca, memasukkan data ke dalam bentuk tabel dan histogram, dan membuat kesimpulan. Berdasarkan hasil penelitian menunjukkan bahwa kemampuan membaca cepat siswa perempuan kelas VIII SMPN 03 Lebong termasuk dalam kategori sedang serta siswa laki-laki kelas VIII SMPN 03 Lebong termasuk kategori lambat sedangkan kemampuan membaca cepat siswa kelas VIII SMPN 03 Lebong secara keseluruhan masuk dalam kategori sedang. Hasil penelitian ini diharapkan menjadi evaluasi guru bahasa Indonesia untuk terus meningkatkan kemampuan membaca cepat siswa, baik siswa laki-laki maupun perempuan agar kemampuan literasi siswa meningkat.
\end{abstract}

Kata kunci: kemampuan membaca cepat, jenis kelamin, siswa SMP 


\title{
The Ability to Read Fast Based on the Gender of Class VIII SMP Negeri 03 Lebong Academic Year 2020/2021
}

\begin{abstract}
The ability to read quickly is the ability of students to read quickly and with correct understanding. The better the students' ability to read quickly, the better the understanding of the reading content. However, it is not yet known whether there is a difference in speed reading abilities between male and female students against the text they read. For this reason, the purpose of this study was to describe the level of speed reading ability based on the gender of the eighth grade students of SMP Negeri 03 Lebong in the academic year 2020/2021. This research method using quantitative descriptive method. The population is 24 students and the sample is all members of the population, which is 24 students consisting of 12 male students and 12 female students. The data collection technique used a test technique in the form of a multiple choice test. Data analysis techniques by calculating student understanding and percentage, calculating effective reading speed, entering data into tables and histograms, and making conclusions. Based on the results of the study, it shows that the fast reading ability of female students of class VIII SMPN 03 Lebong is in the medium category and male students of class VIII of SMPN 03 Lebong are in the slow category while the fast reading ability of grade VIII students of SMPN 03 Lebong is in the medium category as a whole. The results of this study are expected to be an evaluation of Indonesian language teachers to continue to improve students 'speed reading skills, both male and female students so that students' literacy skills increase.
\end{abstract}

Kata kunci: speed reading ability, gender, junior high school students

\section{A. Pendahuluan}

Tantangan masyarakat pada abad ke-21 dalam menghadapi globalisasi yaitu kemampuan literasi khususnya kemampuan membaca dan menulis. Di dalam buku "Literasi Baca Tulis" yang disusun oleh Kementerian Pendidikan dan Kebudayaan (2017:1) menyebutkan bahwa literasi dasar, kompetensi, dan kualitas karakter harus sejalan dengan pendidikan nasional pada abad ke-21 sehingga nantinya sanggup unggul dan berkiprah serta berpartisipasi di tengah globalisasi dan regionalisasi.

Kegiatan literasi memiliki peran dalam meningkatkan minat membaca dan menulis siswa di dalam kelas maupun di rumah. Dari kegiatan literasi ini, siswa mendapatkan manfaat dan secara tidak langsung memotivasi siswa untuk menyukai kegiatan membaca dan menulis semakin meningkat. Minat membaca dan menulis siswa melalui kegiatan literasi dapat diterapakan dengan kedisiplinan, pembiasaan membaca siswa, dan pemilihan metode pembelajaran yang tepat oleh guru.

Salah satu kegiatan membaca yang dapat dilakukan untuk meningkatkan kemampuan membaca siswa yaitu membaca cepat. Membaca cepat merupakan kegiatan membaca yang dilakukan dengan waktu yang sesingkat-singkatnya dengan keseimbangan perolehan pemahaman bacaan secara tepat. Kemampuan dalam membaca setiap siswa berbeda dari satu siswa dengan siswa yang lain. PISA (Programme for International Student Assessment), menyebutkan bahwasannnya hasil dari kemampuan membaca siswa perempuan lebih unggul daripada anak laki-laki. Penelitian ini dilakukan dari tahun 2000 pada 32 Negara 
Fera Delva, Dian Eka Chandra Wardhana, Rokhmat Basuki

Kemampuan Membaca Cepat Berdasarkan Jenis Kelamin Siswa Kelas VIII SMP Negeri 03 Lebong Tahun Pelajaran 2020/2021

(the Organization for Economic Cooperation and Development (OECD, 2001). Menurut OECD (2001) dalam penelitiannya yang melibatkan 57 negara, didapatkan hasil penelitian bahwa skor rata-rata siswa perempuan lebih baik daripada siswa laki-laki. Seperti contoh, di negara Kanada, kemampaun membaca siswa perempuan 551, sedangkan laki-laki 519. Penelitian lain juga menyebutkan bahwa dalam hal membaca dan menulis, perempuan lebih unggul daripada lakilaki. PISA kemudian mengadakan penelitian lain pada tahun 2003 melibatkan 40 negara dan tahun 2006, 56 negara, hasil penelitian menunjukkan bahwa anak perempuan memiliki skor lebih tinggi daripada nak laki-laki dalam kemampuan membaca (OECD, 2003; OECD, 2006).

Penelitian tentang membaca cepat oleh Purwaningsih (2020:3) membuktikan bahwa penggunaan metode SQ3R dapat meningkatkan kemamapuan membaca siswa. Hasil penelitian menunjukkan rata-rata kecepatan baca siswa pada siklus I yaitu $140 \mathrm{kpm}$ dan rata-rata persentase pemahaman isi bacaan $54 \%$, sedangkan pada siklus II, rata-rata kecepatan baca pada siklus II yaitu $175 \mathrm{kpm}$, rata-rata persentase pamahaman isi bacaan yaitu $90 \%$. Hal ini membuktikan bahwa semakin cepat kemampuan membaca cepat seseorang, maka semakin tinggi pemahaman terhadap isi bacaan.

Penelitian lain oleh Amalia (2019:12) menunjukkan bahwa semakin banyak pengalaman membaca siswa, maka semakin bagus pula hasil pemahaman yang di dapat. Penelitian ini melalui 3 siklus dengan menggunakan teknik skimming. Hasilnya terjadi peningkatan kemampuan membaca pada setiap siklus. Kedua penelitian ini dilakukan secara umum dan merupakan penelitian PTK yang dilakukan pada tingkat SMA.

Sejalan dengan hasil penelitian tersebut, Tarigan (1985:122) menyatakan dalam bukunya yaitu ada dua cara yang dapat dilakukan untuk memiliki kosakata secara efektif yaitu melalui pengalaman dan bacaan. Salah satu aspek keterampilan berbahasa yaitu kemampuan membaca cepat sangat penting untuk dikuasai siswa, khususnya pada literasi baca-tulis dalam menyongsong abad ke21 ini.

Somadayo (2011:1) menyatakan pendapatnya bahwasannya buku, majalah, surat kabar, artikel internet atau dokumen tertulis lainnya yang merupakan informasi yang akan disajikan dalam bentuk wacana tertulis. Seiring dengan hal tersebut, manusia dituntut agar dapat mengikuti laju perkembangan zaman dengan diimbangi oleh kemampuan membaca yang memadai.

Dalam hal ini, kemampuan membaca yang memadai dapat tercapai jika diikuti dengan pemahaman terhadap bacaan. Oleh karena itu, seseorang dapat dikatakan berhasil dalam membaca jika dia sudah memahami isi bacaannya (Sari dkk., 2020; Hermanudin dkk., 2019). Memahami bacaan merupakan suatu kegiatan membaca yang dilakukan dengan memahami isi bacaan secara mendalam sehingga pembaca dapat menemukan berbagai ilmu pengetahuan dan informasi yang terdapat dalam bacaan.Perlu diketahui bahwasannya setiap orang sesuai dengan tingkat pendidikan akan memiliki kemampuan membaca berbeda satu sama lainnya. Ada beberapa orang yang membaca buku dengan sangat cepat dan ada pula yang akan membaca buku dengan lambat atau secara lambat. 
Fera Delva, Dian Eka Chandra Wardhana, Rokhmat Basuki

Kemampuan Membaca Cepat Berdasarkan Jenis Kelamin Siswa Kelas VIII SMP Negeri 03 Lebong Tahun Pelajaran 2020/2021

Tampubolon (1990:6) memberikan pendapatnya bahwasannya membaca merupakan satu dari empat kemampuan berbahasa, dan merupakan satu bagian dari komunikasi tulisan. Dalman (2013:5) menjelaskan bahwa membaca merupakan suatu kegiatan atau proses kognitif yang berupaya untuk menemukan berbagai informasi yang terdapat dalam tulisan sehingga dari informasi-informasi tersebut tentunya akan menambah wawasan para pembaca sehingga tergantung dengan kebutuhan bacaannya. Membaca akan menjadi suatu kebutuhan dasar untuk masyarakat untuk terus maju, berkembang, dan semakin bergerak ke arah positif. Demikian pula halnya dalam dunia pendidikan, peranan membaca sangat berpengaruh terhadap proses, hasil, dan prestasi siswa. Terampil dalam membaca dapat menjadikan siswa memahami dengan baik semua materi pelajaran yang disajikan saat proses pembelajaran.

Dalman (2013:18) lebih lanjut menjelaskan bahwa sekolah sebaiknya menjadikan pembelajaran membaca difokuskan pada aspek kemampuan memahami isi bacaan. Jadi, dalam hal ini penekanan akan siswa untuk memahami isi bacaan dari informasi atau buku yang mereka baca akan terpahami oleh mereka sehingga kegiatan latihan membaca merupakan hal yang penting dalam membaca cepat karena selain dapat membaca secara cepat, latihan juga dapat membantu dalam hal penguasaan kosakata. Sebab, ketika seseorang mempunyai pengusaan kosakata yang bagus, maka pekerjaan membaca yang mereka lakukan tidak akan sia-sia dikarenakan informasi yang dibaca dapat langsung mereka dapatkan dengan baik, sebab kata-kata sulit dan istilah-istilah dalam bacaan itu sudah dapat mereka pahami.

Kemampuan membaca cepat merupakan keterampilan yang penting bagi siswa untuk melatih keterampilan berpikir siswa sehingga siswa mampu dengan tepat menemukan informasi yang tersirat dalam suatu bacaan. Nurhadi (2013:31) menjelaskan bahwa kemampuan membaca cepat ialah jenis membaca yang mengutamakan kecepatan, dengan tidak meninggalkan pemahaman terhadap aspek bacaannya. Artinya, penilaian tidak hanya dilihat dari seberapa kecepatan si pembaca, tetapi juga dengan melihat seberapa besar tingkat pemahaman pembaca tersebut terhadap bacaanya. Tingkat pemahaman tersebut bisa dilihat dengan menggunakan tes-tes sesuai dengan materi bacaan.

Subyantoro (2011:2) juga mengungkapkan bahwa untuk memperoleh informasi dari sumber manapun, ada satu kemampuan yang dituntut dan tak berubah yaitu kemampuan membaca dari si pencari informasi. Kemampuan membaca bukan hanya sekedar dapat membaca, melainkan bagaimana membaca secara cepat dan memahami isinya.

SMP Negeri 3 Lebong adalah SMP yang telah menggunakan Kurikulum 2013 yang artinya pembelajaran bahasa Indonesia sudah dipusatkan pada teks. Tentunya, dalam hal ini kemampuan membaca para siswa harus lebih baik lagi, agar siswa mampu memahami isi teks dengan cepat dan tepat. Berdasarkan hasil wawancara penulis dengan Kepala Perpustakaan SMPN 03 Lebong, yaitu ibu Fenti, minat membaca anak rata-rata di SMP Negeri 03 Lebong ini bisa dikatagorikan kategori kurang yang ditandai dengan sepinya perpustakaan saat 
Fera Delva, Dian Eka Chandra Wardhana, Rokhmat Basuki

Kemampuan Membaca Cepat Berdasarkan Jenis Kelamin Siswa Kelas VIII SMP Negeri 03 Lebong Tahun Pelajaran 2020/2021

jam istirahat atau jam kosong ditandai dengan catatan buku kunjungan di SMPN 03 Lebong.

Kemudian, penulis juga melakukan kegiatan wawancara kepada guru bahasa Indonesia lain yaitu Bapak Hero. Pada wawancara ini, ia menyebutkan bahwa pembelajaran membaca telah menjadi aspek kegiatan yang dilakukan oleh guru untuk menambah dan mendapatkan ilmu pengetahuan. Selain itu, bapak Hero juga menyebutkan bahwa kegiatan membaca juga dilakukan agar dapat menambah kosakata siswa-siswa di SMP Negeri 03 Lebong. Kegiatan membaca ini rencananya juga akan menjadi kegiatan rutin yang dilakukan siswa-siswa setiap pagi karena untuk menerapkan dan menjalankan literasi baca-tulis.

Sayangnya, pemahaman membaca siswa di SMP Negeri 03 Lebong ini juga belum mencapai KKM yang ditargetkan Sekolah. Hal ini dibuktikan dengan beberapa nilai-nilai siswa saat ujian tengah semester ataupun ujian akhir semester yang belum lulus sehingga siswa-siswa tersebut menjalani ujian remedial. Oleh karena itu, penelitian mengenai kemampuan membaca cepat yang diimbangi dengan pemahaman dirasa pas di SMPN 03 Lebong ini.

Kegiatan membaca cepat akan menjadi bagian dari aspek pengajaran membaca yang diajarkan oleh guru di sekolahnya, tidak hanya itu untuk melatih kemampuan membaca pada siswanya, guru juga menganjurkan siswa untuk membaca dari berbagai sumber. Selain hal tersebut, penulis memilih kelas VIII berdasarkan hasil belajar siswa dalam Mata Pelajaran Bahasa Indonesia.

Kelas VIII merupakan kelas yang sudah mempunyai pojok baca di kelas. Selain itu, Kelas VIII merupakan kelas yang memiliki nilai rata-rata bahasa Indonesia tertinggi di antara kelas lainnya, kemudian kelas tersebut juga merupakan salah satu kelas yang diajarkan oleh penulis sehingga penulis mengetahui bagaimana perkembangan membaca pada seluruh siswa tersebut.

Sejalan dengan hal-hal yang telah dianalisis penulis pada SMP Negeri 03 lebong, penulis juga menemukan beberapa pendapat ahli yaitu Tarigan (1985:2) menjelaskan kualitas keterampilan berbahasa seseorang bergantung kepada kuantitas dan kualitas kosakata yang dimilikinya. Selanjutnya Djiwandono (2008:43) juga berpendapat bahwasanya pemahaman yang tepat terhadap pesan yang disampaikan melalui bahasa, banyak ditentukan oleh pemahaman yang tepat terhadap kosakata yang digunakan di dalamnya.

Penelitian membaca cepat sudah pernah dilakukan oleh Mayeni (2020) tentang kemampuan membaca cepat dengan kemampuan berbahasa Indonesia siswa kelas VII SMP Negeri 2 Ranah Pesisir Kabupaten Pesisir Selatan. Penelitian relevan juga sudah dilakukan oleh Slamet (2018) melalui penelitian tindakan kelas tentang peningkatkan kemampuan membaca cepat melalui metode latihan di kelas VIII A SMP Negeri 2 Darma. Kemudian, penelitian Inawati dan Sanjaya (2018) tentang kemampuan membaca cepat dan pemahaman siswa kelas v SD Negeri Oku. Dari beberapa penelitian terdahulu, terdapat beberapa perbedaan akan muncul pada penelitian penulis seperti variabel penelitian, populasi dan sampel, objek penelitian dan meteode penelitiannya. Perbedaan lain yang mencolok yaitu penulis akan lebih condong kepada penelitian membaca cepat berdasarkan jenis kalamin yaitu siswa perempuan dan siswa laki-laki. 
Fera Delva, Dian Eka Chandra Wardhana, Rokhmat Basuki

Kemampuan Membaca Cepat Berdasarkan Jenis Kelamin Siswa Kelas VIII SMP Negeri 03 Lebong Tahun Pelajaran 2020/2021

Berdasarkan faktor yang telah penulis sebutkan, penulis tertarik untuk melihat kemampuan membaca cepat siswa. Dalam penelitian ini, penulis memilih SMP Negeri 03 Lebong karena sekolah ini telah menerapkan Kurikulum 2013. Pada Kurikulum 2013 ini, kegiatan membaca cepat menjadi salah satu aspek pengajaran materi mengenai pembelajaran membaca berbasis teks yang sekolah jalankan. Sekolah ini juga menerapkan literasi baca tulis yaitu kegiatan membaca 15 menit sebelum memulai pembelajaran khususnya kelas VIII dan kelas tersebut juga sudah mempunyai pojok baca. Selain hal tersebut, penulis memilih kelas VIII berdasarkan hasil belajar siswa dalam Mata Pelajaran Bahasa Indonesia. Berdasarkan hal tersebut penulis mengharapkan hasil yang optimal dari penelitian ini sehingga dapat menjadi kelas percontohan bagi kelas lainnya untuk lebih meningkatkan prestasi belajarnya.

\section{B. Metodologi Penelitian}

Metode penelitian yang digunakan adalah metode deskriptif kuantitatif. Metode penelitian kuantitatif merupakan metode penelitian yang dimaksudkan untuk menjelaskan fenomena dengan menggunakan data-data numerik, kemudian dianalisis yang umumnya menggunakan statistik. Sugiyono (2013:23) mengemukakan bahwa metode penelitian kuantitatif digunakan untuk meneliti pada populasi atau sampel tertentu, pengumpulan data menggunakan instrumen penelitian, analisis data bersifat kuantitatif/ statistik, dengan tujuan menguji hipotesis yang telah ditetapkan. Hal ini berarti bahwa penelitian ini akan menggambarkan suatu gejala dari data yang bersifat kuantitatif. Data yang bersifat kuantitatif yaitu kemampuan Kecepatan Efektif Membaca (KEM) yang dideskripsikan atau dicari skor reratanya. Hasil skor tersebut juga dapat dikategorikan sehingga diperoleh frekuensi dan persentase yang diharapkan.

Populasi dalam penelitian ini adalah siswa kelas VIII SMP Negeri 03 Lebong yang terdiri dari 24 siswa. Dalam penelitian ini sampel yang akan diambil adalah dengan teknik purposive sampling atau sampel bertujuan yaitu dengan menentukan kriteria berdasarkan pembagian jenis kelamin. Maka berdasarkan jenis kelamin jumlah sampel sebesar 24 siswa yang terdiri atas 12 siswa perempuan dan 12 siswa laki-laki.

Teknik pengumpulan data menggunakan tes. Instrumen tes berbentuk tes pilihan ganda yang diperoleh dari hasil kemampuan membaca cepat teks. Instrumen tes kemampuan membaca cepat sebelum digunakan diuji tingkat validitas dan reliabilitasnya pada siswa di luar sampel sehingga tingkat keterbacaannya baik. Tes terdiri dari 4 teks bacaan yang masing-masing memiliki tema yang berbeda dengan jumlah soal setiap dari setiap teks yaitu 10 soal sehingga berjumlah 40 soal.

Teknik analisis data menggunakan langkah-langkah berikut: menghitung pemahaman siswa dan dipersentasekan, menghitung Kecepatan Efektif Membaca (KEM) dengan cara membagi jumlah kata dalam teks dengan jumlah waktu baca dalam satuan menit dikali dengan persentase pemahaman, memasukkan data ke dalam bentuk tabel dan histogram, serta membuat kesimpulan hasil penelitian. 
Fera Delva, Dian Eka Chandra Wardhana, Rokhmat Basuki

Kemampuan Membaca Cepat Berdasarkan Jenis Kelamin Siswa Kelas VIII SMP Negeri 03 Lebong Tahun Pelajaran 2020/2021

Pedoman penilaian Kecepatan Efektif Membaca (KEM) menurut Dalman (2013:45) dapat dilihat pada tabel berikut.

Tabel 1. Pedoman Penilaian Kecepatan Efektif Membaca (KEM)

\begin{tabular}{ccl}
\hline No. & \multicolumn{1}{c}{ Kecepatan Efektif Membaca } & \multicolumn{1}{c}{ Kategori } \\
\hline 1. & $189-227 \mathrm{KPM}$ & Sangat cepat \\
\hline 2. & $111-149 \mathrm{KPM}$ & Cepat \\
\hline 3. & $200-250 \mathrm{KPM}$ & Sedang \\
\hline 4. & $72-110 \mathrm{KPM}$ & Lambat \\
\hline 5. & $33-71 \mathrm{KPM}$ & Sangat lambat \\
\hline
\end{tabular}

\section{Hasil Penelitian dan Pembahasan}

1. Hasil Penelitian

a. Hasil Kemampuan Membaca Cepat Siswa Perempuan

Hasil kemampuan membaca cepat siswa perempuan dapat ditunjukkan pada tabel berikut.

Tabel 2. Kemampuan Membaca Cepat Siswa Perempuan

\begin{tabular}{|c|c|c|c|c|c|c|c|c|}
\hline \multirow[b]{2}{*}{ No. } & \multirow[b]{2}{*}{ Nama } & \multirow[b]{2}{*}{ No Induk } & \multicolumn{6}{|c|}{ KEM (K/Wm X B/SI) } \\
\hline & & & $\begin{array}{c}\text { TEKS } \\
1\end{array}$ & $\begin{array}{c}\text { TEKS } \\
2 \\
\end{array}$ & $\begin{array}{c}\text { TEKS } \\
3 \\
\end{array}$ & $\begin{array}{c}\text { TEKS } \\
4\end{array}$ & $\begin{array}{c}\text { TEKS } \\
5\end{array}$ & RATA-RATA \\
\hline 1 & $\begin{array}{l}\text { Anjelia } \\
\text { Montika }\end{array}$ & 0075944281 & $\begin{array}{c}137 \\
\text { KPM } \\
\end{array}$ & $\begin{array}{c}121 \\
\text { KPM } \\
\end{array}$ & $\begin{array}{c}118 \\
\text { KPM }\end{array}$ & $\begin{array}{c}113 \\
\text { KPM } \\
\end{array}$ & $\begin{array}{c}121 \\
\text { KPM } \\
\end{array}$ & $122 \mathrm{KPM}(\mathrm{S})$ \\
\hline 2 & Elvi Yulita & 0065712376 & $\begin{array}{c}111 \\
\text { KPM }\end{array}$ & $\begin{array}{c}120 \\
\text { KPM }\end{array}$ & $\begin{array}{r}123 \\
\text { KPM } \\
\end{array}$ & $\begin{array}{c}104 \\
\text { KPM }\end{array}$ & $\begin{array}{c}103 \\
\text { KPM }\end{array}$ & 112 KPM (S) \\
\hline 3 & Julia & 0065178500 & $\begin{array}{c}163 \\
\text { KPM }\end{array}$ & $\begin{array}{c}161 \\
\text { KPM }\end{array}$ & $\begin{array}{c}127 \\
\text { KPM }\end{array}$ & $\begin{array}{c}140 \\
\text { KPM }\end{array}$ & $\begin{array}{c}144 \\
\text { KPM }\end{array}$ & $147 \mathrm{KPM}(\mathrm{S})$ \\
\hline 4 & $\begin{array}{l}\text { Karisa } \\
\text { Sapitri }\end{array}$ & 0088933069 & $\begin{array}{c}157 \\
\text { KPM }\end{array}$ & $\begin{array}{c}155 \\
\text { KPM }\end{array}$ & $\begin{array}{c}161 \\
\text { KPM }\end{array}$ & $\begin{array}{c}134 \\
\text { KPM }\end{array}$ & $\begin{array}{c}162 \\
\text { KPM }\end{array}$ & 145 KPM (S) \\
\hline 5 & $\begin{array}{l}\text { Olimpia } \\
\text { Angriani }\end{array}$ & 0055019363 & $\begin{array}{c}75 \\
\text { KPM }\end{array}$ & $\begin{array}{c}85 \\
\text { KPM }\end{array}$ & $\begin{array}{c}92 \\
\text { KPM }\end{array}$ & $\begin{array}{c}78 \\
\text { KPM }\end{array}$ & $\begin{array}{c}96 \\
\text { KPM }\end{array}$ & 85 KPM (L) \\
\hline 6 & $\begin{array}{l}\text { Pilda } \\
\text { Santika }\end{array}$ & 0087054973 & $\begin{array}{c}133 \\
\text { KPM }\end{array}$ & $\begin{array}{c}112 \\
\text { KPM }\end{array}$ & $\begin{array}{c}99 \\
\text { KPM }\end{array}$ & $\begin{array}{c}112 \\
\text { KPM }\end{array}$ & $\begin{array}{c}115 \\
\text { KPM }\end{array}$ & 114 KPM (S) \\
\hline 7 & $\begin{array}{l}\text { Pinka } \\
\text { Aretha } \\
\text { Dzakirah }\end{array}$ & 0077696982 & $\begin{array}{c}149 \\
\text { KPM } \\
\end{array}$ & $\begin{array}{c}99 \\
\text { KPM } \\
\end{array}$ & $\begin{array}{c}124 \\
\text { KPM }\end{array}$ & $\begin{array}{r}108 \\
\text { KPM } \\
\end{array}$ & $\begin{array}{c}114 \\
\text { KPM }\end{array}$ & 119 KPM (S) \\
\hline 8 & $\begin{array}{l}\text { Rara } \\
\text { Anjelia }\end{array}$ & 0065539343 & $\begin{array}{c}145 \\
\text { KPM }\end{array}$ & $\begin{array}{c}137 \\
\text { KPM }\end{array}$ & $\begin{array}{c}118 \\
\text { KPM }\end{array}$ & $\begin{array}{c}117 \\
\text { KPM }\end{array}$ & $\begin{array}{c}122 \\
\text { KPM }\end{array}$ & $128 \mathrm{KPM}(\mathrm{S})$ \\
\hline 9 & $\begin{array}{l}\text { Repa } \\
\text { Ulandari }\end{array}$ & 0066854842 & $\begin{array}{c}134 \\
\text { KPM }\end{array}$ & $\begin{array}{c}128 \\
\text { KPM }\end{array}$ & $\begin{array}{c}105 \\
\text { KPM }\end{array}$ & $\begin{array}{c}119 \\
\text { KPM }\end{array}$ & $\begin{array}{c}130 \\
\text { KPM }\end{array}$ & 123 KPM (S) \\
\hline 10 & $\begin{array}{l}\text { Rina } \\
\text { Amelia }\end{array}$ & 0071762346 & $\begin{array}{c}151 \\
\text { KPM }\end{array}$ & $\begin{array}{c}136 \\
\text { KPM }\end{array}$ & $\begin{array}{c}108 \\
\text { KPM }\end{array}$ & $\begin{array}{c}112 \\
\text { KPM }\end{array}$ & $\begin{array}{c}115 \\
\text { KPM }\end{array}$ & $124 \mathrm{KPM}(\mathrm{S})$ \\
\hline 11 & $\begin{array}{l}\text { Weliya } \\
\text { Yunita }\end{array}$ & 0052820382 & $\begin{array}{c}79 \\
\text { KPM }\end{array}$ & $\begin{array}{c}137 \\
\text { KPM }\end{array}$ & $\begin{array}{c}85 \\
\text { KPM }\end{array}$ & $\begin{array}{c}112 \\
\text { KPM }\end{array}$ & $\begin{array}{c}104 \\
\text { KPM }\end{array}$ & 103 KPM (L) \\
\hline 12 & $\begin{array}{l}\text { Wika } \\
\text { Riyanti }\end{array}$ & 0087092007 & $\begin{array}{c}126 \\
\text { KPM } \\
\end{array}$ & $\begin{array}{c}120 \\
\text { KPM } \\
\end{array}$ & $\begin{array}{c}136 \\
\text { KPM }\end{array}$ & $\begin{array}{c}119 \\
\text { KPM } \\
\end{array}$ & $\begin{array}{c}117 \\
\text { KPM } \\
\end{array}$ & $124 \mathrm{KPM}(\mathrm{S})$ \\
\hline & Rata & & $\begin{array}{c}130 \\
\text { KPM }\end{array}$ & $\begin{array}{c}126 \\
\text { KPM }\end{array}$ & $\begin{array}{l}116,3 \\
\text { KPM }\end{array}$ & $\begin{array}{c}114 \\
\text { KPM }\end{array}$ & $\begin{array}{c}120 \\
\text { KPM }\end{array}$ & $\begin{array}{c}121 \text { KPM (S) } \\
\text { (Sedang) }\end{array}$ \\
\hline
\end{tabular}

Tabel 2 menunjukkan bahwa rata-rata hasil tes kemampuan membaca cepat siswa perempuan kelas VIII SMPN 03 Lebong pada teks 1 bidang budaya dengan judul "Tari Kejei" yaitu 130 KPM, teks 2 bidang teknologi dengan judul

Silampari Bisa: Jurnal Penelitian Pendidikan Bahasa Indonesia, Daerah, dan Asing Vol. 4, No. 1, June 2021 
Fera Delva, Dian Eka Chandra Wardhana, Rokhmat Basuki

Kemampuan Membaca Cepat Berdasarkan Jenis Kelamin Siswa Kelas VIII SMP Negeri 03 Lebong Tahun Pelajaran 2020/2021

"Pekembangan Teknologi Media Sosial" yaitu 126 KPM, teks 3 bidang sastra dengan judul "Pulang" yaitu 116,3 KPM, dan teks 4 bidang sains dengan judul "Terjadinya Gempa Bumi" yaitu 114 KPM, serta teks 5 bidang pendidikan dengan judul "Dua Pelajar Indonesia Raih Emas di ICYS 2013" yaitu 120 KPM sehingga rata-rata keseluruhan kemampuan membaca cepat siswa perempuan kelas VIII SMPN 03 Lebong yaitu $121 \mathrm{KPM}$ dengan keterangan kategori sedang. Kemudian untuk skor rata-rata tertinggi yang dicapai oleh siswa perempuan atas nama Julia kelas VIII SMPN 03 Lebong yaitu 147 KPM dengan persentase pemahaman 94\%, selanjutnya skor rata-rata terendah yang dicapai siswa perempuan kelas VIII adalah 85 KPM dengan persentase pemahaman $66 \%$.

Berdasarkan tabel 2 di atas, frekuensi hasil tes kemampuan membaca cepat siswa perempuan kelas VIII SMPN 03 Lebong Tahun Pelajaran 2020/2021 adalah sebagai berikut: frekuensi yang memperoleh skor kategori sangat cepat, cepat, sedang, lambat, dan sangat lambat, yaitu kategori sangat cepat (189-227 KPM) yaitu 0 siswa (0\%), kategori cepat (150-188 KPM) yaitu 0 siswa $(0 \%)$, kategori sedang (111-149 KPM) yaitu 10 siswa (83\%), kategori lambat (72-110) yaitu 2 siswa (17\%), dan kategori sangat lambat (33-71) yaitu 0 siswa $(0 \%)$.

Berdasarkan penjelasan di atas maka dapat digambarkan dalam bentuk histogram sebagai berikut.

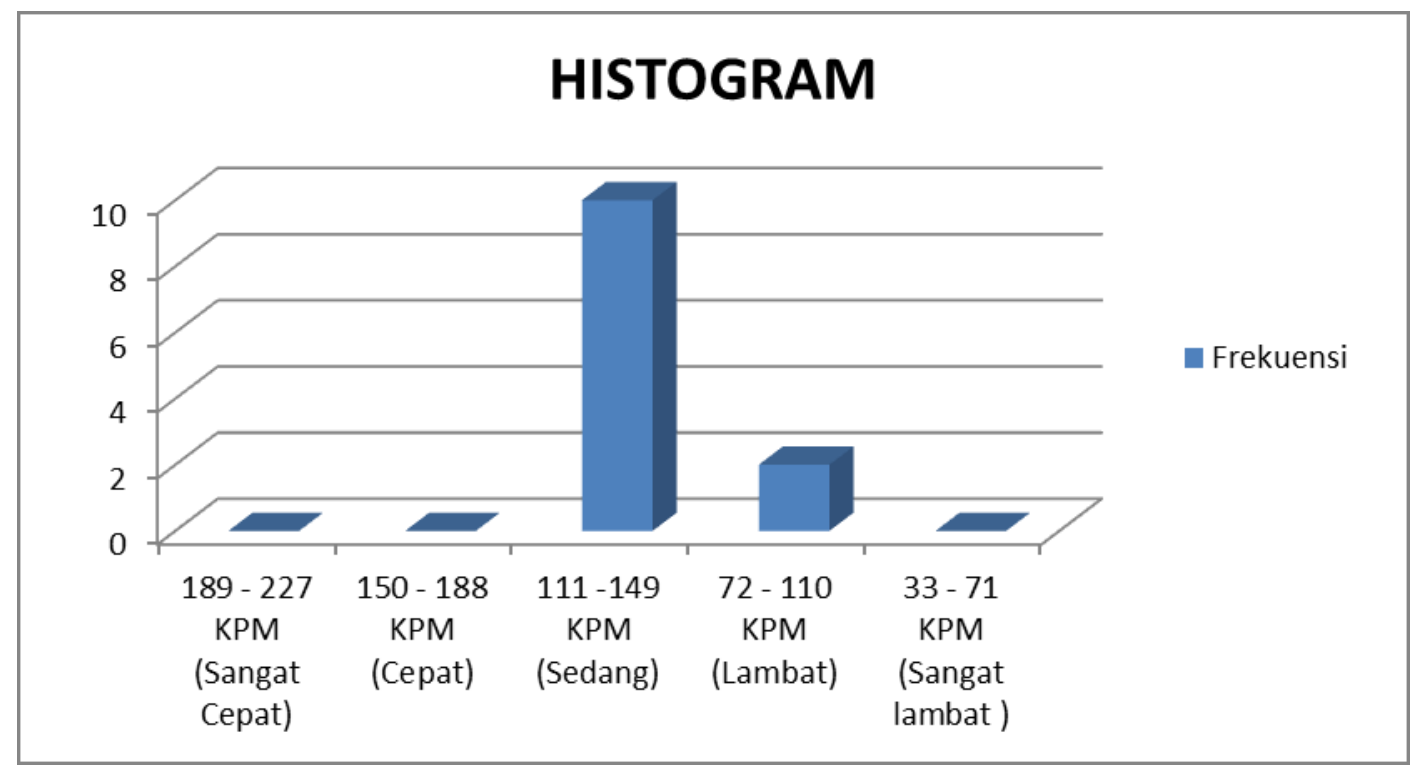

Gambar 1. Histogram Hasil Tes Kemampuan Membaca Cepat Siswa Perempuan Kelas VIII SMPN 03 Lebong Tahun pelajaran 2020/2021

Gambar histogram 1 menunjukkan bahwa hasil tes kemampuan membaca cepat siswa perempuan kelas VIII SMPN 03 Lebong Tahun Pelajaran 2020/2021 sebagai berikut: kemampuan sangat cepat (189-227 KPM) yaitu 0 siswa $(0 \%)$, kemampuan cepat (150-188 KPM) yaitu 0 siswa $(0 \%)$, kemampuan sedang (111149 KPM) yaitu 10 siswa (83\%), kemampuan lambat (72-110) yaitu 2 siswa (17\%), dan kemampuan sangat lambat (33-71) yaitu 0 siswa $(0 \%)$. 
Fera Delva, Dian Eka Chandra Wardhana, Rokhmat Basuki

Kemampuan Membaca Cepat Berdasarkan Jenis Kelamin Siswa Kelas VIII SMP Negeri 03 Lebong Tahun Pelajaran 2020/2021

b. Hasil Kemampuan Membaca Cepat Siswa Laki-Laki

Hasil kemampuan membaca cepat siswa laki-laki dapat ditunjukkan pada tabel berikut.

Tabel 3. Kemampuan Membaca Cepat Siswa Laki-Laki

\begin{tabular}{|c|c|c|c|c|c|c|c|c|}
\hline \multirow{3}{*}{ No. } & \multirow{3}{*}{ Nama } & \multirow{3}{*}{ No Induk } & \multicolumn{6}{|c|}{$\mathrm{KEM}(\mathrm{K} / \mathrm{Wm} \times \mathrm{B} / \mathrm{SI})$} \\
\hline & & & & TEKS & TEKS & TEKS & TEKS & RATA- \\
\hline & & & TEKS 1 & 2 & 3 & 4 & 5 & RATA \\
\hline 1 & Adimai Sa'agni & 0072719588 & $83 \mathrm{KPM}$ & $\begin{array}{c}95 \\
\text { KPM }\end{array}$ & $\begin{array}{c}119 \\
\text { KPM }\end{array}$ & $\begin{array}{c}70 \\
\text { KPM }\end{array}$ & $\begin{array}{c}87 \\
\text { KPM }\end{array}$ & 91 KPM \\
\hline 2 & Agutian Alfikri & 0061157932 & 75 KPM & $\begin{array}{c}113 \\
\text { KPM }\end{array}$ & $\begin{array}{c}97 \\
\text { KPM }\end{array}$ & $\begin{array}{c}89 \\
\text { KPM }\end{array}$ & $\begin{array}{c}113 \\
\text { KPM }\end{array}$ & 98 KPM \\
\hline 3 & Agustiawan & 0063571239 & 79 KPM & $\begin{array}{c}103 \\
\text { KPM }\end{array}$ & $\begin{array}{c}94 \\
\text { KPM }\end{array}$ & $\begin{array}{c}58 \\
\text { KPM }\end{array}$ & $\begin{array}{c}96 \\
\text { KPM }\end{array}$ & 86 KPM \\
\hline 4 & Deri Pratisto & 0076734651 & $47 \mathrm{KPM}$ & $\begin{array}{c}99 \\
\text { KPM }\end{array}$ & $\begin{array}{c}102 \\
\text { KPM }\end{array}$ & $\begin{array}{c}81 \\
\text { KPM }\end{array}$ & $\begin{array}{c}87 \\
\text { KPM }\end{array}$ & 83 KPM \\
\hline 5 & $\begin{array}{l}\text { Muhammad } \\
\text { Danar }\end{array}$ & 0076681239 & $\begin{array}{l}135 \\
\text { KPM }\end{array}$ & $\begin{array}{l}155 \\
\text { KPM }\end{array}$ & $\begin{array}{c}142 \\
\text { KPM }\end{array}$ & $\begin{array}{c}140 \\
\text { KPM }\end{array}$ & $\begin{array}{c}130 \\
\text { KPM }\end{array}$ & $141 \mathrm{KPM}$ \\
\hline 6 & Osshar Olvonsho & 0078765123 & $70 \mathrm{KPM}$ & $\begin{array}{c}96 \\
\text { KPM }\end{array}$ & $\begin{array}{c}75 \\
\text { KPM }\end{array}$ & $\begin{array}{c}56 \\
\text { KPM }\end{array}$ & $\begin{array}{c}100 \\
\text { KPM }\end{array}$ & 80 KPM \\
\hline 7 & Parizal & 0059714434 & $69 \mathrm{KPM}$ & $\begin{array}{c}96 \\
\text { KPM }\end{array}$ & $\begin{array}{c}97 \\
\text { KPM }\end{array}$ & $\begin{array}{c}101 \\
\text { KPM }\end{array}$ & $\begin{array}{c}86 \\
\text { KPM }\end{array}$ & $90 \mathrm{KPM}$ \\
\hline 8 & Prengki Winando & 0078255495 & $\begin{array}{l}108 \\
\text { KPM }\end{array}$ & $\begin{array}{c}129 \\
\text { KPM }\end{array}$ & $\begin{array}{c}80 \\
\text { KPM }\end{array}$ & $\begin{array}{c}84 \\
\text { KPM }\end{array}$ & $\begin{array}{c}97 \\
\text { KPM }\end{array}$ & $100 \mathrm{KPM}$ \\
\hline 9 & Reval Gio Fani & 0067090646 & $99 \mathrm{KPM}$ & $\begin{array}{c}107 \\
\text { KPM } \\
\end{array}$ & $\begin{array}{c}119 \\
\text { KPM }\end{array}$ & $\begin{array}{c}88 \\
\text { KPM }\end{array}$ & $\begin{array}{c}107 \\
\text { KPM }\end{array}$ & $104 \mathrm{KPM}$ \\
\hline 10 & Risky Ramadhan & 0068270749 & 94 KPM & $\begin{array}{c}103 \\
\text { KPM }\end{array}$ & $\begin{array}{c}103 \\
\text { KPM }\end{array}$ & $\begin{array}{c}87 \\
\text { KPM }\end{array}$ & $\begin{array}{c}103 \\
\text { KPM }\end{array}$ & 98 KPM \\
\hline 11 & $\begin{array}{l}\text { Yoga Septa } \\
\text { Dwinata }\end{array}$ & 0071811851 & $\begin{array}{c}134 \\
\text { KPM }\end{array}$ & $\begin{array}{c}128 \\
\text { KPM }\end{array}$ & $\begin{array}{c}125 \\
\text { KPM }\end{array}$ & $\begin{array}{c}117 \\
\text { KPM }\end{array}$ & $\begin{array}{c}123 \\
\text { KPM }\end{array}$ & $125 \mathrm{KPM}$ \\
\hline 12 & Zacky Abdul Aziz & 0085515713 & $\begin{array}{c}151 \\
\text { KPM }\end{array}$ & $\begin{array}{c}167 \\
\text { KPM }\end{array}$ & $\begin{array}{c}151 \\
\text { KPM }\end{array}$ & $\begin{array}{c}129 \\
\text { KPM }\end{array}$ & $\begin{array}{c}133 \\
\text { KPM }\end{array}$ & $146 \mathrm{KPM}$ \\
\hline & Rata-Rata & & $\begin{array}{r}95,3 \\
\text { KPM }\end{array}$ & $\begin{array}{c}116 \\
\text { KPM } \\
\end{array}$ & $\begin{array}{c}109 \\
\text { KPM }\end{array}$ & $\begin{array}{c}92 \\
\text { KPM }\end{array}$ & $\begin{array}{c}105 \\
\text { KPM }\end{array}$ & $\begin{array}{l}103 \mathrm{KPM} \\
\text { (Lambat) }\end{array}$ \\
\hline
\end{tabular}

Tabel 3 menunjukkan bahwa rata-rata hasil tes kemampuan membaca cepat siswa laki-laki kelas VIII SMPN 03 Lebong pada teks 1 bidang budaya dengan judul "Tari Kejei" yaitu 95,3 KPM, teks 2 bidang teknologi dengan judul "Pekembangan Teknologi Media Sosial" yaitu 116 KPM, teks 3 bidang sastra dengan judul "Pulang" yaitu 109 KPM, dan teks 4 bidang sains dengan judul "Terjadinya Gempa Bumi" yaitu 92 KPM, serta teks 5 bidang pendidikan dengan judul "Dua Pelajar Indonesia Raih Emas di ICYS 2013" yaitu 105 KPM sehingga rata-rata keselururahn kemampuan membaca cepat siswa laki-laki kelas VIII SMPN 03 Lebong yaitu $121 \mathrm{KPM}$ dengan keterangan kategori lambat. Kemudian untuk skor rata-rata tertinggi yang dicapai oleh siswa laki-laki atas nama Zaki Abdul Aziz kelas VIII SMPN 03 Lebong yaitu 146 KPM dengan persentase pemahaman $88 \%$, selanjutnya skor rata-rata terendah yang dicapai siswa laki-laki atas nama Osshr Olvonso kelas VIII adalah $80 \mathrm{KPM}$ dengan persentase pemahaman $46 \%$.

Berdasarkan tabel 3 di atas frekuensi hasil tes kemampuan membaca cepat siswa perempuan kelas VIII SMPN 03 Lebong Tahun Pelajaran 2020/2021 
sebagai berikut: frekuensi yang memperoleh skor kategori sangat cepat, cepat, sedang, lambat dan sangat lambat, yaitu kategori sangat cepat (189-227 KPM) yaitu 0 siswa (0\%), kategori cepat (150-188 KPM) yaitu 0 siswa (0\%), kategori sedang (111-149 KPM) yaitu 3 siswa (25\%), kategori lambat (72-110) yaitu 9 siswa (75\%), dan kategori sangat lambat (33-71) yaitu 0 siswa (0\%).

Berdasarkan penjelasan di atas maka dapat digambarkan dalam bentuk histogram sebagai berikut.

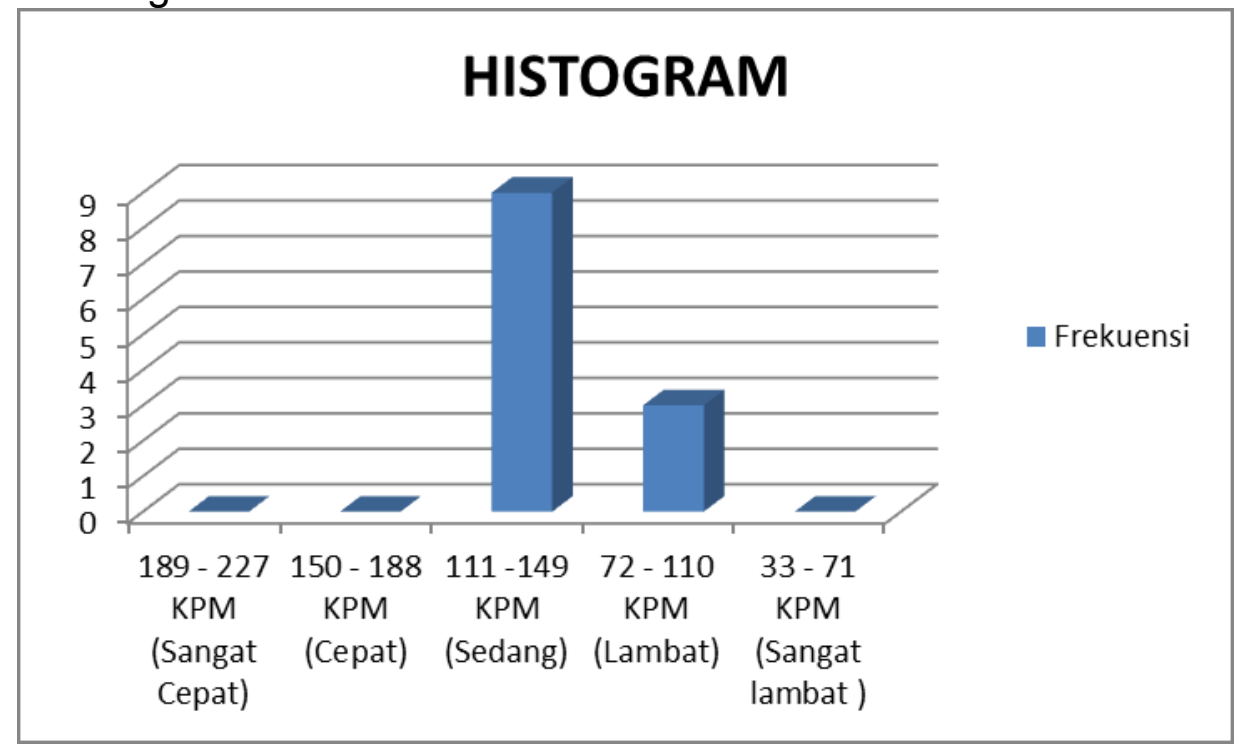

Gambar 2. Histogram Hasil Tes Kemampuan Membaca Cepat Siswa Laki-Laki Kelas VIII SMPN 03 Lebong

Gambar histogram 2 menunjukkan bahwa hasil tes kemampuan membaca cepat siswa perempuan kelas VIII SMPN 03 Lebong Tahun Pelajran 2020/2021 sebagai berikut: kemampuan sangat cepat (189-227 KPM) yaitu 0 siswa (0\%), kemampuan cepat (150-188 KPM) yaitu 0 siswa (0\%), kemampuan sedang (111149 KPM) yaitu 3 siswa (25\%), kemampuan lambat (72-110) yaitu 9 siswa (7\%), dan kemampuan sangat lambat (33-71) yaitu 0 siswa (0\%).

\section{Pembahasan}

Hasil penelitian menunjukkan bahwa hasil tes kemampuan membaca cepat siswa kelas VIII SMPN 03 Lebong Tahun pelajaran 2020/2021 pada teks 1 bidang budaya yang berjudul "Tari Kejei" adalah skor tertinggi yang dicapai oleh siswa perempuan yaitu $163 \mathrm{KPM}$ dengan persentase pemahaman 90\%, selanjutnya skor terendah yang dicapai oleh siswa laki-laki yaitu $47 \mathrm{KPM}$ dengan persentase pemahaman $60 \%$ dan waktu baca, dan rata-rata kemampuan membaca cepat mahasiswa pada teks 1 ini adalah sebesar 113 KPM (kategori sedang).

Hasil tes kemampuan membaca cepat siswa kelas VIII SMPN 03 Lebong Tahun pelajaran 2020/2021 pada teks 2 bidang teknologi yang berjudul "Perkembangan Teknologi Media Sosial" adalah skor tertinggi yang dicapai oleh siswa laki-laki yaitu $167 \mathrm{KPM}$ dengan persentase pemahaman 90\%, selanjutnya 
Fera Delva, Dian Eka Chandra Wardhana, Rokhmat Basuki

Kemampuan Membaca Cepat Berdasarkan Jenis Kelamin Siswa Kelas VIII SMP Negeri 03 Lebong Tahun Pelajaran 2020/2021

skor terendah yang dicapai siswa perempuan yaitu 85 KPM dengan persentase pemahaman $60 \%$, serta rata-rata kemampuan membaca cepat pada teks 2 ini adalah sebesar $130 \mathrm{KPM}$ (kategori sedang).

Hasil tes kemampuan membaca cepat siswa kelas VIII SMPN 03 Lebong Tahun pelajaran 2020/2021 pada teks 3 bidang Sastra dengan judul "Pulang" adalah skor tertinggi yang dicapai oleh siswa perempuan yaitu 161 KPM dengan persentase pemahaman $100 \%$, selanjutnya skor terendah yang dicapai siswa laki-laki adalah $75 \mathrm{KPM}$ dengan persentase $\mathrm{p}$ emahaman $40 \%$, serta rara-rata sebesar 112,5 KPM (kategori sedang).

Hasil tes kemampuan membaca cepat siswa kelas VIII SMPN 03 Lebong Tahun pelajaran 2020/2021 pada teks 4 bidang Sains dengan judul "Terjadinya Gempa Bumi" adalah skor tertinggi yang dicapai oleh siswa perempuan yaitu 140 KPM dengan persentase pemahaman $90 \%$, selanjutnya skor terendah yang dicapai siswa laki-laki adalah 56 KPM dengan persentase pemahaman 40\%, serta rata-rata kemampuan membaca cepat siswa pada teks 4 adalah sebesar 103 KPM (kategori lambat).

Hasil tes kemampuan membaca cepat siswa kelas VIII SMPN 03 Lebong Tahun pelajaran 2020/2021 pada teks 5 bidang pendidikan dengan judul "Dua Pelajar Indonesia Raih Emas di ICYS 2013"adalah skor tertinggi yang dicapai oleh siswa perempuan yaitu 162 KPM dengan persentase pemahaman $100 \%$, selanjutnya skor terendah yang dicapai siswa laki-laki adalah 86 KPM dengan persentase pemahaman $60 \%$, serta rata-rata kecepatan membaca siswa pada teks 5 adalah sebesar 113 KPM (kategori sedang).

Secara keseluruhan, berdasarkan hasil kemamuan membaca cepat siswa kelas VIII SMPN 03 Lebong Tahun pelajaran 2020/2021 dari teks 1 sampai dengan teks 5 maka dapat diperoleh rata-rata keseluruhan siswa perempuan mendapatkan rata-rata kategori sedang dan siswa laki-laki mendapatkan kategori lambat. Kemudian, kemampuan keseluruhan siswa kelas VIII dalam membaca cepat siswa menunjukkan skor sebesar 113,3 KPM (kategori sedang)

Hasil penelitian yang diperoleh menunjukkan bahwa kemampuan membaca siswa kelas VIII SMPN 03 Lebong Tahun pelajaran 2020/2021 untuk siswa perempuan kelas VIII sudah sesuai dengan jenjang pendidikan mereka, KEM siswa yang diperoleh dalam penelitian ini adalah kategori sedang sesuai kualifikasi KEM siswa yang seharusnya. Sedangkan untuk siswa laki-laki kelas VIII belum mencapai KEM yang seharusnya didapatkan, KEM siswa laki-laki yang diperoleh dalam penelitian ini termasuk ke dalam kualifikasi KEM siswa katagori lambat.

Dalman (2013:45) menjelaskan bahwa untuk siswa kualifikasi KEM antara lain sebagai berikut: kategori sangat cepat (189-227 KPM), kategori cepat (150188 KPM), kategori sedang (111-149 KPM), kategori lambat (72-110) dan kategori sangat lambat (33-71). Berdasarkan pendapat Dalman tersebut kualifikasi KEM siswa kelas VIII SMPN 03 Lebong Tahun pelajaran 2020/2021 Kabupaten Lebong untuk siswa perempuan berada pada kategori sedang dan sudah memadai, sedangkan untuk siswa laki-laki berada pada kategori lambat atau belum memadai. 
Fera Delva, Dian Eka Chandra Wardhana, Rokhmat Basuki

Kemampuan Membaca Cepat Berdasarkan Jenis Kelamin Siswa Kelas VIII SMP Negeri 03 Lebong Tahun Pelajaran 2020/2021

Hasil penelitian ini merujuk pada pendapat Gurian (2010) yang menyatakan bahwa adanya perbedaan struktur otak, baik pada perempuan maupun pada lakilaki. Hal itu menyebabkan anak perempuan mempunyai kemampuan verbal yang lebih tinggi. Sedangkan menurut Benbow (dalam Gurian, 2010) menjelaskan bahwa selain adanya perbedaan struktur otak, budaya juga memiliki peranan penting dalam menentukan keunggulan pada anak perempuan dan laki-laki masing-masing. Contohnya, di beberapa tempat menganggap bahwa budaya membaca merupakan kegiatan yang sifatnya feminim.

Hasil yang diperoleh penulis yaitu rata-rata kemampuan membaca siswa laki-laki yaitu dalam kategori lambat. Hal ini terjadi kemungkinan besar berhubungan dengan faktor-faktor yang menjadi penghambat membaca cepat seperti minat baca yang kurang karena menurut Dalman (2013:141) bahwa minat baca akan mempengaruhi pemahaman terhadap isi bacaan. Dari hasil penelitian menunjukkan bahwa beberapa siswa laki-laki yang membutuhkan waktu baca yang lama untuk memahami isi bacaan, kesulitan memahami dengan cepat bisa dipengaruhi oleh minat baca yang kurang. Selain itu, kurangnya konsentrasi juga dapat mempengaruhi kemampuan membaca cepat. Konsentrasi sangat diperlukan ketika membaca cepat dikarenakan agar kita trfokus pada apa yang di baca.

Selain minat Widiatmoko (2011:28) menjelaskan bahwa yang dapat mempengruhi kecepatan membaca juga seperti: (1) pengalaman, (2) bahasa, (3) metode, dan (4) tujuan. Sejalan dengan pendapat Widiatmoko tersebut, minat baca yang kurang sehingga berpengaruh pada pengalaman dalam membaca menjjadi kurang karena tidak ada pengalaman dalam membaca atau hanya sedikit pengalaman dalam membaca.

Selain itu, bahasa dalam teks juga berpengaruh daam kecepatan membaca dan pemahaman membaca. Seperti pada teks bidang pendidikan yang berjudul "Dua Pelajar Indonesia Raih Emas di ICYS 2013 ", di dalam teks ini banyak mengguankan kosakata bahasa Inggris sehingga kemungkinan pembaca sulit melafalkan kata tersebut dan membuat waktu baca menjadi lama. Hal tersebut sebenarnya dapat diatasi yaitu dengan menggunakan teknik dalam membaca. Ada beberpa teknik yang bisa digunakan dalam membaca yang menggunakan kosakata yang sulit. Salah satunya menggunakan teknik dalam buku Dalman (2013:15) dalam bukunya mengatakan ada empat teknik. Pertama yaitu teknik baca-pilih yaitu dengan cara memilih bahan bacaan yang berisikan informasi yang ingin dicari/ditemukan, teknik baca-lompat yaitu hampir sama dengan baca pilih, mencari informasi yang diperlukan dan melompat bagian yang lain, teknik bacalayap yaitu membaca dengan cepat untuk mengetahui isi umum bacaan tersebut dan teknik baca-tatap yaitu teknik dengan cara memusatkan perhatian untuk menemukan bagian bacaan yang terdapat informasi yang ingin ditemukan.

Sedangkan siswa laki-laki, ketika penulis bertanya bagaimana mereka membaca kosakata bahasa Inggris disebutkan bahwa mereka tidak menggunakan satu teknik pun. Hal tersebut penulis tanyakan kepada siswa-siswa apakah ketika membaca mereka menggunakan teknik, hampir keseluruhan mereka membaca tanpa teknik. 
Fera Delva, Dian Eka Chandra Wardhana, Rokhmat Basuki

Kemampuan Membaca Cepat Berdasarkan Jenis Kelamin Siswa Kelas VIII SMP Negeri 03 Lebong Tahun Pelajaran 2020/2021

Kemudian tujuan. Ketika seorang pembaca mempunyai tujuan saat membaca, maka pembaca tersebut akan sangat bersemangat dalam membaca. Dalam hal ini, kemungkinan siswa laki-laki tidak terlalu menganggap tes KEM ini penting sehingga mereka menganggap bahwa tes ini tidak terlalu penting dan mereka tidak mempunyai tujuan tertentu dalam tes ini. Siswa tersebut kemungkinan hanya membaca sesuai perintah tanpa memahami isi teks tersebut sehingga membuat nilai pemahaman pun menjadi rendah.

Selain itu, juga kebiasaan dalam membaca pun dapat menjadi faktor yang menyebabkan tidak dapat membaca cepat sperti yang dijelaskan oleh Soedarso (2001:6) faktor-faktor penghambat membaca cepat diantaranya yaitu: vokalisasi yang berarti membaca dengan bersuara, gerakan bibir yaitu kebiasaan komatkamit ketika membaca, gerakan kepala, menunjuk dengan jari, regresi yang berarti kebiasaan selalu membaca ulang kata atau beberapa kata, dan subvokalisasi yaitu melafalkan dalam pikiran kata-kata yang dibaca. Kebiasaankebiasaan tersebut jika sering dilakukan oleh para siswa akan menyebabkan tidak akan mampu meningkatkan kemampuan membaca cepat mereka. Kebiasankebiasaan ini yang menurut kita dapat membantu dalam memahami bacaan akan menjadi penghambat dalam kecepatan membaca.

Minat baca yang kurang, kebiasaan buruk dalam membaca, dan tidak adanya teknik dalam membaca serta membaca dengan bersuara, gerakan bibir yaitu kebiasaan komat-kamit ketika membaca, gerakan kepala, menunjuk dengan jari, regresi kemungkinan besar menjadi penyebab kemampuan membaca cepat siswa Laki-Laki Kelas VIII SMPN 03 masuk dalam kategori lambat.

Beberapa teknik dan cara yang bisa dilakukan oleh guru dalam mengatasi permasalahan di atas menurut Dalman (2013:15) dan Ahmad (2010:79) yaitu dengan menggunakan teknik membaca yaitu baca-pilih (selecting) siswa dapat memilih bahan bacaan atau bagian bacaan yang dianggapnya relevan, atau berisi informasi fokus yang ditentukannya. Kemudian, baca-lompat (skipping), di sini siswa hanya menemukan bagian atau bagian-bagian bacaan yang relevan, melalui atau melompati bagian-bagian lain. Hal ini dilakukan agar siswa tidak hanya fokus pada satu atau beberapa kata yang sulit sehingga menghambat kecepatan membaca. Kemudian, baca-layap (skimming) yaitu siswa membaca dengan cepat untuk mengetahui isi umum suatu bacaan atau bagiannya. Isi umum yang dimaksud mungkin adalah informasi fokus, tetapi mungkin juga hanya sebagai dasar untuk menduga apakan bacaan atau bagian bacaan itu berisi informasi yang telah ditentukan. Pilihan lain yang dapat guru berikan yaitu dengan teknik baca-tatap (scanning) yaitu membaca dengan cepat dan dengan memusatkan perhatian untuk menemukan bagian bacaan yang berisi informasi fokus yang telah ditentukan, dan seterusnya membaca bagian itu dengan teliti sehingga informasi fokus itu ditemukan dengan tepat dan dipehami benar.

Hasil penelitian ini tentulah berbeda dengan hasil penelitian sebelumnya oleh peneliti lain. Pada penelitian dari Inawati dan Sanjaya (2018) tentang kemampuan membaca cepat dan pemahaman siswa Kelas V SD Negeri Oku. Hasil penelitiannya yaitu SDN 1 OKU diketahui 17 siswa kecepatan membacanya sedang, 23 siswa kecepatannya rendah. Berbeda dengan hasil penelitian ini yang difokuskan pada kemampuan membaca cepat berdasarkan jenis kelamin dengan 
Fera Delva, Dian Eka Chandra Wardhana, Rokhmat Basuki

Kemampuan Membaca Cepat Berdasarkan Jenis Kelamin Siswa Kelas VIII SMP Negeri 03 Lebong Tahun Pelajaran 2020/2021

hasil penelitian yaitu rata-rata KEM yang diperoleh oleh siswa perempuan kelas VIII SMPN 03 Lebong Tahun Pelajaran 2020/2021 yaitu 121 KPM termasuk pada kategori sedang dan rata-rata KEM yang diperoleh oleh siswa laki-laki yaitu 103 KPM termasuk pada kategori lambat.

\section{Simpulan}

Berdasarkan data yang diperoleh dan hasil analisis yang dilakukan maka dapat ditarik kesimpulan kemampuan membaca cepat berdasarkan jenis kelamin menunjukkan hasil rata-rata KEM yang diperoleh oleh siswa perempuan kelas VIII SMPN 03 Lebong Tahun Pelajaran 2020/2021 yaitu 121 KPM. Hasil rata-rata kemampuan membaca cepat setiap teksnya yaitu: teks 1 sebesar $130 \mathrm{KPM}$, teks 2 sebesar $126 \mathrm{KPM}$, teks 3 sebesar 116,3 KPM, teks 4 sebesar $114 \mathrm{KPM}$, teks 5 sebesar $120 \mathrm{KPM}$ dengan hasil keseluruhan yaitu kategori sedang (111-149 KPM) diperoleh 10 siswa (83\%), dan kategori lambat (72-110) diperoleh 2 siswa (17\%) sehingga dapat disimpulkan bahwa kemampuan membaca cepat siswa perempuan kelas VIII SMPN 03 Lebong Tahun Pelajaran 2020/2021 termasuk pada kategori sedang.

Kemudian, rata-rata KEM yang diperoleh oleh siswa laki-laki kelas VIII SMPN 03 Lebong Tahun Pelajaran 2020/2021 yaitu 103 KPM. Hasil rata-rata kemampuan membaca cepat setiap teksnya yaitu: Teks 1 sebesar 95,3 KPM, teks 2 sebesar $116 \mathrm{KPM}$, teks 3 sebesar $109 \mathrm{KPM}$, teks 4 sebesar $92 \mathrm{KPM}$, teks 5 sebesar $105 \mathrm{KPM}$ dengan hasil rata-rata setiap siswa untuk keseluruhan teks adalah kategori sedang (111-149 KPM) diperoleh 3 siswa (25\%), dan kategori lambat (72-110) diperoleh 9 siswa (75\%). Secara keseluruhan dapat disimpulakan bahwa kemampuan membaca cepat siswa laki-Laki kelas VIII SMPN 03 Lebong Tahun Pelajaran 2020/2021 termasuk pada kategori lambat.

Dari hasil penelitian ini diharapkan kepada guru bahasa Indonesia dapat memperhatikan kembali soal yang akan diberikan kepada siswa setelah kegiatan membaca dilakukan. Guru dapat menguji dahulu tingkat validitas dan reliabilitas dari soal yang akan diberikan kepada siswa agar soal yang diberikan sesuai dengan tingkat dan kemampuan.

Untuk membantu proses kemampuan membaca cepat yang dimiliki oleh siswa dapat juga dengan memberikan beberapa latihan dan kemudian bisa diberikan penugasan seperti resume, sinopsis, dan lain-lain. Selanjutnya, guru mampu menumbuhkan minat, motivasi, dan mengajarkan beberapa teknik dalam membaca kepada para siswa. Sebagai seorang guru juga harus memberikan banyak informasi pengetahuan mengenai membaca cepat, baik teori maupun praktik sehingga siswa dapat mengetahui, memahami, dan menguasai serta menerapkan kegiatan membaca cepat divmana saja dan kapan saja.

Kemudian, diharapkan juga bagi peneliti yang lain dapat melakukan penelitian lanjutan tentang kemampuan membaca cepat siswa baik di SD maupun SMP serta SMP di Kabupaten Lebong. Penelitian lanjutan dapat juga menjelaskan faktor-faktor perbedaan penghambat membaca cepat yang pasti berdasarkan jenis kelamin. Selanjutnya penelitian ini juga dapat dilanjutkan dengan penelitian 
Fera Delva, Dian Eka Chandra Wardhana, Rokhmat Basuki

Kemampuan Membaca Cepat Berdasarkan Jenis Kelamin Siswa Kelas VIII SMP Negeri 03 Lebong Tahun Pelajaran 2020/2021

yang lain yang sesuai dan berkenaan dengan empat keterampilan berbahasa yaitu menyimak, menulis dan berbicara.

\section{Daftar Pustaka}

Ahmad, L. (2010). Speed Reading Teknik dan Metode Membaca Cepat. Yogyakarta: A Plus Books.

Amalia, F. N. (2019). Peningkatan Keterampilan Membaca Cepat dengan Teknik Skimming. Jurnal IImiah Bina Edukasi, 12(01), 31-41. doi:10.33557/jedukasi.v12i01.479

Dalman. (2013). Keterampilan Membaca. Jakarta: PT Raja Grafindo Persada.

Djiwandono, M. S. (2008). Tes Bahasa dalam Pengajaran. Jakarta: Indeks.

Gurian, M. (2010). Boys and Girls Learn Differently: A Guide for Teachers and Parents. Amerika Serikat: Amazon.

Hermanudin, Suhartono, Suryadi, \& Noermanzah. (2019). Improvement of Reading Comprehension Ability by Using Core Models of Class VII a Students of SMP Negeri 10 Bengkulu Tengah. International Journal of Scientific and Technology Research, 8(12).

Kementerian Pendidikan dan Kebudayaan. (2017). Literasi Baca Tulis. Jakarta: TIM GLN Kemendikbud.

Mayeni, R. (2020). Kemampuan Membaca Cepat dengan Kemampuan Berbahasa Indonesia Siswa Kelas VII SMP Negeri 2 Ranah Pesisir Kabupaten Pesisir Selatan. Jurnal Kepemimpinan dan Pengurusan Sekolah, 5(1), 49-56. doi:10.34125/kp.v5i1.464

Nurhadi. (2013). Membaca Cepat dan Efektif. Bandung: Sinar Baru Algensindo.

OECD. (2006). Assesing Scientific, Reading, and Mathematical Literacy : A Framework for PISA 2006. USA: OECD Publishing.

OECD. (2001). Knowledge and Skills for Life: First Results from the OECD Programme for International Student Assessment (PISA) 2000. USA: OECD-PISA.

OECD. (2003). Literacy Skills for the World of Tomorrow: Further Results from PISA 2000. Paris: Unesco Institue for Statistic.

Purwaningsih, S. (2020). Penggunaan SQ3R dalam Meningkatkan Kemampuan Membaca Cepat. Dinamika, 3(2), 74. doi:10.35194/jd.v3i2.1002 
Sari, M.H., Susetyo, Noermanzah, Wardhana, D.E.C., Kusumaningsih, D. (2020). Understanding the Level of Students' Reading Comprehension Ability. Universal Journal of Educational Research, 8(5). https://doi.org/10.13189/ujer.2020.080521

Slamet, M. (2018). Meningkatkan Kemampuan Membaca Cepat melalui Metode Latihan di Kelas VIII A SMP Negeri 2 Darma. FON: Jurnal Pendidikan Bahasa dan Sastra Indonesia, 13(2). doi:10.25134/fjpbsi.v13i2.1547

Soedarso. (2001). Sistem Membaca Cepat dan Efektif. Jakarta: Gramedia Pustaka Utama.

Somadayo, S. (2011). Strategi dan Teknik Pembelajaran Membaca. Yogyakarta: Graha Ilmu.

Subyantoro. (2011). Pengembangan Keterampilan Membaca Cepat. Jogjakarta: Graha IImu.

Sugiyono. (2013). Metode Penelitian Pendidikan Pendekatan Kauntitaif, Kualitaif, dan R\&D. Bandung: ALFABETA.

Tampubolon. (1990). Kemampuan Membaca Teknik Membaca Efektif dan Efisien. Bandung: Angkasa.

Tarigan, H. G. (1985). Pengajaran Kosakata. Bandung: Angkasa.

Widiatmoko, I. (2011). Super Speed Reading Metode Lengkap dan Praktis untuk Meningkatkan Kemampuan Membaca. Jakarta: PT Gramedia Pustaka Utama. 